\title{
NON-DESTRUCTIVE EVALUATION OF A DIESTE'S HISTORICAL REINFORCED BRICK MASONRY CHURCH
}

\author{
LEANDRO D. DOMENECH, AGUSTÍN SPALVIER, GONZALO MOLTINI, \\ ALINA B. AULET \& GONZALO P. CETRANGOLO* \\ Instituto de Estructuras y Transporte, Universidad de la República, Uruguay
}

\begin{abstract}
The concept and use of reinforced brick masonry (RBM) has a long history. Engineer Eladio Dieste was one of the most renowned innovators in the RBM field. One of Dieste's outstanding RBM buildings is Church of Christ the Worker (1958-1960) in Atlántida, Uruguay. Even though the structure has been maintained by the local community, it has begun to show signs of aging. In August 2016 the church was selected by Keeping It Modern, an international grant program developed by the Getty Foundation with focus on the conservation of important buildings. This article presents the inspection of Dieste's church, by means of visual inspection and non-destructive evaluation (NDE), performed under this program. Several NDE techniques - infrared thermography, ground penetrating radar, penetration resistance and ultrasonic testing - were applied to assess the state of conservation of the structure. The visual inspection and NDE yielded results associated with various symptoms of initiated deterioration mechanisms: presence of moisture, corrosion of some steel bars and degradation of mortars. Despite these pathologies that are commonly present in aged RBM structures, the church is in a good state of preservation. This fact reveals the impressive care with which it was designed and built.
\end{abstract}

Keywords: Eladio Dieste, evaluation, historical structure, NDE, reinforced brick masonry

\section{INTRODUCTION}

Masonry is bonded to the beginning of architecture and civil engineering, since it represents the first structural system used by humanity. For thousands of years, plain masonry allowed the construction not only of homes but also of works of impressive beauty and grandeur [1]. Nevertheless, the potential of this constructive system is limited by its low tensile strength, which makes it inadequate for structural elements such as beams, slabs and columns subjected to eccentric loads. To overcome this shortcoming, plain masonry is strengthened with reinforcing materials such as steel bars, giving rise to reinforced masonry [2].

Owing to its composite nature, reinforced brick masonry (RBM) has allowed to shape many buildings in which traditional non-reinforced masonry was not an option. The principles behind RBM are the same as those commonly accepted for reinforced concrete: steel reinforcement significantly increases tensile and shear strength as well as the ductility of the brick masonry, broadening the possibilities of its application in civil engineering [1].

One of the most renowned innovators of the RBM field was engineer Eladio Dieste [3, 4]. During his active years, he designed and built more than 200 structures, pushing the composite material to the limit [5]. Some of his innovations were the invention and construction of different types of vaults - many having breathtakingly optimized geometries - e.g. the 'Gaussian' double-curvature vaults $[6,7]$; the reinforcement of masonry by fine wire meshes arranged in its joints [4]; and the development of various techniques for prestressing an RBM structure with remarkable simplicity [8]. The value of his work is extraordinary from both a structural engineering and architectural standpoint. For these reasons, his works have become an emblematic artistic and cultural legacy of Uruguay [3, 4].

Dieste's first architectural work, Church of Christ the Worker, is a fundamental piece of that legacy. Built between 1958 and 1960 in Atlántida, Uruguay, the church was conceived 
in response to the modest commission of an entrepreneur, who would donate the work to the local community. Dieste took the challenge and was able to shape an extraordinary RBM structure, which seats 300 people, spending similar budget as the common industrial sheds [9]. This was made possible by optimizing the structural design and construction process.

A schematic plan of the church is shown in Figure 1. At floor level, its plan is a simple rectangle of $16 \times 33 \mathrm{~m}$ [9], from which double wythe brick undulating walls, of $7 \mathrm{~m}$ high and $30 \mathrm{~cm}$ width [4], rise to the maximum amplitude of their arcs. These self-stabilizing walls carry continuous double-curvature vaults, of $11 \mathrm{~cm}$ total width [9], with tie rods concealed in the valleys that are anchored in the brick edge beams [10]. The floor-level space contains the confessionals, nave, chancel, chapel, sacristy and anti-sacristy. The baptistery is located underground, while the bell tower stands near the west façade.

Even though the structure has been maintained by the local community, it has begun to show signs of ageing. In August 2016 the church was selected by Keeping It Modern, an international grant initiative programme developed by the Getty Foundation. This programme annually supports around ten projects of outstanding significance that promise to advance conservation practices on important buildings of the 20th century [11]. Within this framework, a working group was established with the objective of creating a conservation plan and an administration system of Dieste's church. One of the subgroups of the working group is responsible for the detection of pathologies and damage of the structure.

The objective of this article is to present the methodology and results of the inspection of the church, performed by means of visual inspection and non-destructive evaluation (NDE). NDE results improve knowledge of the structure's condition and allow making better decisions regarding the application of forthcoming maintenance tasks.

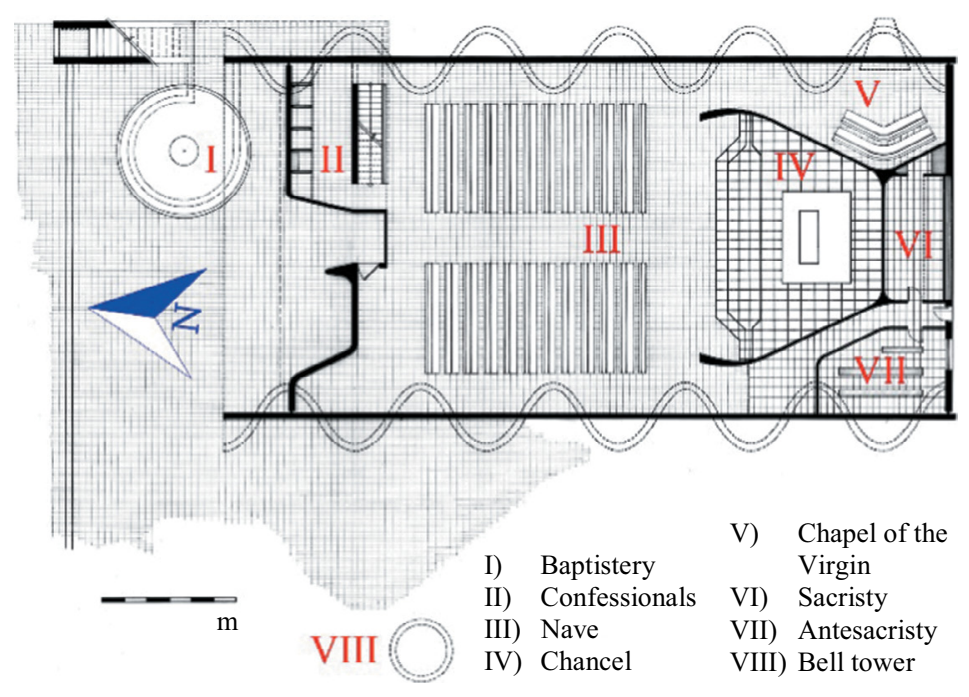

Figure 1: Original plan of Church of Christ the Worker. 


\section{METHODOLOGY}

The methodology followed to assess the state of conservation of the structure can be divided into two stages: visual inspection and NDE. The latter was carried out by means of four different NDE techniques: infrared thermography, ground penetrating radar (GPR), penetration resistance and ultrasonic testing.

\subsection{Visual Inspection}

Visual inspection is the most important non-destructive technique [12]. It involves performing critical observation of the structure's surfaces. In this investigation visual inspection, complemented with digital photography, was carried out at every sector of the building prior to any other NDE technique in order to identify potential deterioration patterns. Once visual inspection was completed, the rest of the non-destructive testing techniques were planned accordingly to the preliminary findings for further interrogation.

Although most of the structure was studied non-destructively, certain locations in the roof were inspected by removing the top materials. This was necessary to expose the principal steel reinforcement and allow direct visual inspection.

\subsection{Non-destructive Testing Techniques}

\subsubsection{Infrared Thermography}

The equipment used in this case was an infrared camera - FLIR E6 - with a thermal image resolution of $120 \times 160$ pixels. This camera, shown in Figure 2a, uses an uncooled

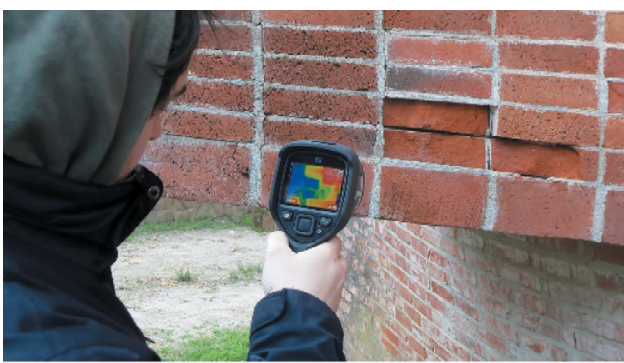

(a)

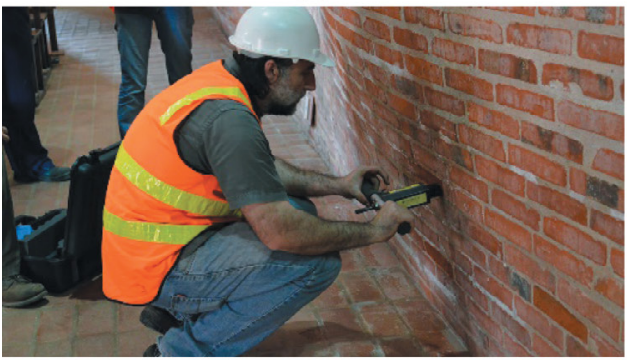

(c)

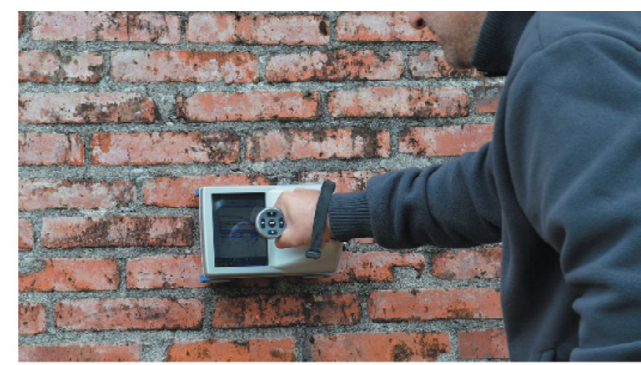

(b)

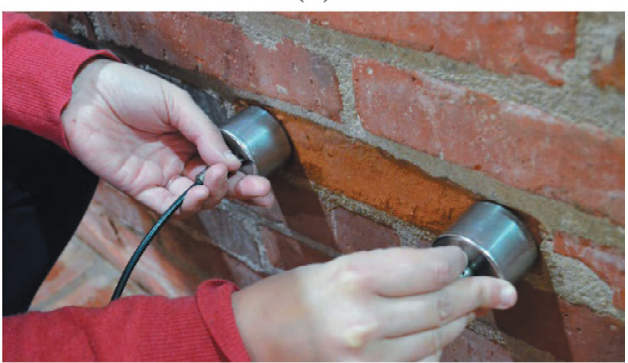

(d)

Figure 2: NDE techniques used in field research: (a) infrared thermography; (b) GPR; (c) penetration resistance and (d) ultrasonic testing. 
microbolometer and is capable of showing a real-time image - with a frame rate of $9 \mathrm{~Hz}$. Two halogen lamps of $300 \mathrm{~W}$ were used in order to make a few tests using an active approach.

Infrared thermography is a relatively low-cost, non-contact, non-intrusive, NDE technique which reveals the surface temperature of an object through the reception of the - nonharmful - infrared radiation that this object emits [13]. The camera sensor detects the total radiation and, using certain parameters that need to be entered by the operator, shows the surface temperature. Thermal radiation can be quantified using the Stefan-Boltzmann equation [14], as presented in eqn (1), where $E$ is the radiation, $e$ the emissivity, $T$ the temperature and $\sigma$ the Stefan-Boltzmann constant $-5.67 \cdot 10^{-8} \mathrm{~W} /\left(\mathrm{m}^{2} \mathrm{~K}^{4}\right)$ :

$$
E=e \cdot \sigma \cdot T^{4}
$$

There are two approaches for obtaining results using this method. First, it is possible to use a passive approach, which consists in observing the structure with no exterior or artificial excitation whatsoever. By applying this approach several differences between zones may be noticed: dissimilar materials with different emissivity show differences in apparent temperature - even if their real temperatures are equal - zones with dissimilar damage show differences compared with undamaged areas, zones with reparations previously executed or with presence of moisture also show differences compared with unaltered zones [15]. In contrast, the active approach consists in using an external energy source.

A first inspection was carried out using the passive approach. The infrared camera was used to obtain images of both the interior and exterior surfaces of the church's walls and roof, and of the baptistery - which was difficult due to the lack of proper illumination. A second inspection was performed looking for certain defects, based on the primary results of the other methods. With respect to the active test, halogen lamps were used to heat the surface and detect the damage extension in brick delamination - zones with different depths show a difference in the temperature after a time. The general method was to heat up an area and monitor the surface temperature from a fixed point of view.

\subsubsection{Ground Penetrating Radar}

A GPR, brand GSSI, model StructureScan Mini was used. This equipment, which is shown in Figure $2 b$, emits and receives electromagnetic (EM) waves with a nominal frequency of 1.6 $\mathrm{GHz}$ and a maximum penetration depth of about $50 \mathrm{~cm}$.

GPR has been used for many years and the principles behind the technique are well documented. The GPR method uses a transmitting antenna that emits EM pulses to the object being analysed. In a simplified way, part of the pulse is reflected back when it encounters an interface with a material with different electric properties [16, 17]. A receiving antenna detects the reflected EM pulse and the time history signal is recorded. Equation (2) - in which $v$ is the velocity, $c$ is the velocity of propagation of light in vacuum and $\varepsilon$ the dielectric constant of the analysed material - represents a simplification of the phenomenon [18] and can be used for high frequencies. In this case, all frequency components travel at the same velocity and suffer the same attenuation [15]. An impulsive signal will travel with its shape intact, which is propagation without dispersion [19]:

$$
v=\frac{c}{\sqrt{\varepsilon}}
$$


Moisture content affects the physical properties of dielectric porous materials and makes their dielectric constant change. The effect on the dielectric constant of ceramic bricks walls by varying their moisture content has been studied previously, where a linear correlation between $\sqrt{\varepsilon}$ and the moisture content $(\omega)$ was obtained [15, 17]. In practice, this relationship results in a variation of the arrival time of the EM pulse reflected on the opposite surface of the wall being evaluated when varying the $\omega$, as presented in Figure 3.

Knowing that the thickness of Dieste's church walls is constant, the relationship between $\sqrt{\varepsilon}$ and $\omega$ presented was used to determine variations in the moisture content of the walls. The NDE technique was carried out along the east and west façades of the church at multiple heights and along the perimeter of the retaining walls of the baptistery. Unfortunately, it could not be performed over the roof, since the EM pulse is totally reflected on a fine wire mesh arranged between the GPR equipment and opposite surface of the wall assessed.

\subsubsection{Penetration Resistance}

The non-destructive - formally semi-destructive - penetration resistance testing technique was carried out by means of a Windsor Pin Test System equipment, developed by James Instruments. A photograph of the equipment is shown in Figure 2c.

This technique is used to evaluate construction materials by penetration resistance tests. A spring drives a steel pin into the surface of the material and its depth of penetration is used as a parameter to characterize the material, since penetration depth is inversely correlated with compressive strength $[20,21]$. Penetration resistance is employed in situ as an indirect method to detect areas with variations of the compressive strength of the material. The method is standardized in Ref. [22] to test hardened concrete and can be applied to masonry evaluation with minor modifications [12].

Windsor Pin was applied on both the bricks and mortars of the east and west façades of the church and of the perimeter of the baptistery's retaining walls. In all cases, a statistically significant number of tests were performed in order to obtain reliable results.

\subsubsection{Ultrasonic Testing}

This investigation used a Pundit Lab - brand Proceq - ultrasonic pulse velocity (UPV) test instrument set with two $54 \mathrm{kHz}$ piezoelectric transducers, as presented in Figure $2 \mathrm{~d}$.

UPV test consists in generating and receiving wave (P-wave) pulses that travel through a solid material under inspection. Pulses are sent and detected using a pair of piezoelectric

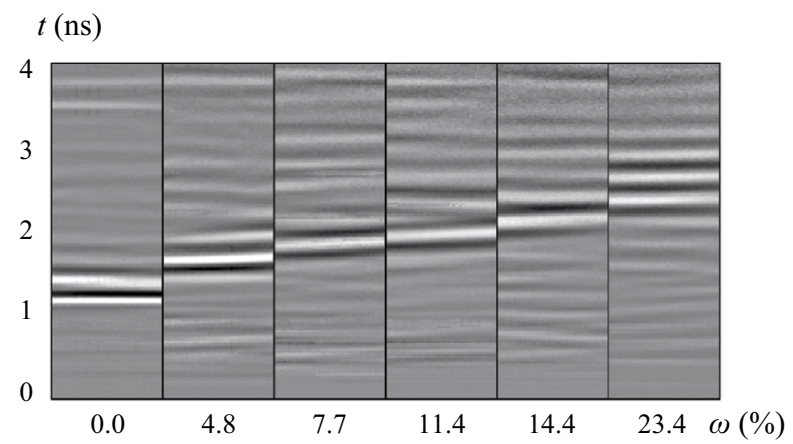

Figure 3: Effect on the travel time ( $t$ ) of the EM pulse of ceramic brick walls by varying their moisture content $(\omega)$, due to the change of $\sqrt{\varepsilon}[15,17]$. 
transducers located at known positions; thus, the distance between them is known. The system allows computing the pulse propagation time. Therefore, the pulses' velocity $v_{\mathrm{p}}$ is estimated using eqn (3), where $\Delta x$ and $\Delta t$ correspond to the distance between transducers and propagation time, respectively [23]:

$$
v_{\mathrm{P}}=\frac{\Delta x}{\Delta t}
$$

UPV has a positive correlation with the material's elastic modulus and compressive strength and, therefore, is an indicative parameter of the material's quality [16]. Low UPV results could indicate the presence of voids, layer detachment, foreign inclusions, disaggregated material, between others, whereas high UPV results indicate good contact between material layers, and high-quality material with good mechanical properties [12]. Reference [24] presents the potentials of this technique for the characterization of local heritage masonry structures.

\section{RESULTS}

\subsection{Visual Inspection}

Overall, as Figure 4 in part shows, Dieste's church is in very good condition. Only particular moderate pathologies were identified at specific locations; these are explained as follows.

Several signs of corrosion with exposed rebar and mortar detachment were observed throughout the building, at the interior and exterior of the church and, particularly, at the baptistery and bell tower. In the case of the church building, these corresponded to secondary horizontal reinforcement along the walls, as Figure 5a shows. Signs of corrosion were also observed at the ceiling, mainly in the valleys. The destructive inspections in the roof exposed the principal steel tie rods in perfect condition without signs of corrosion, as Figure 5b shows. Signs of severe corrosion, with mortar and brick detachment, and mortar patching, indicating previous repairing efforts, were observed in the baptistery's ceiling.

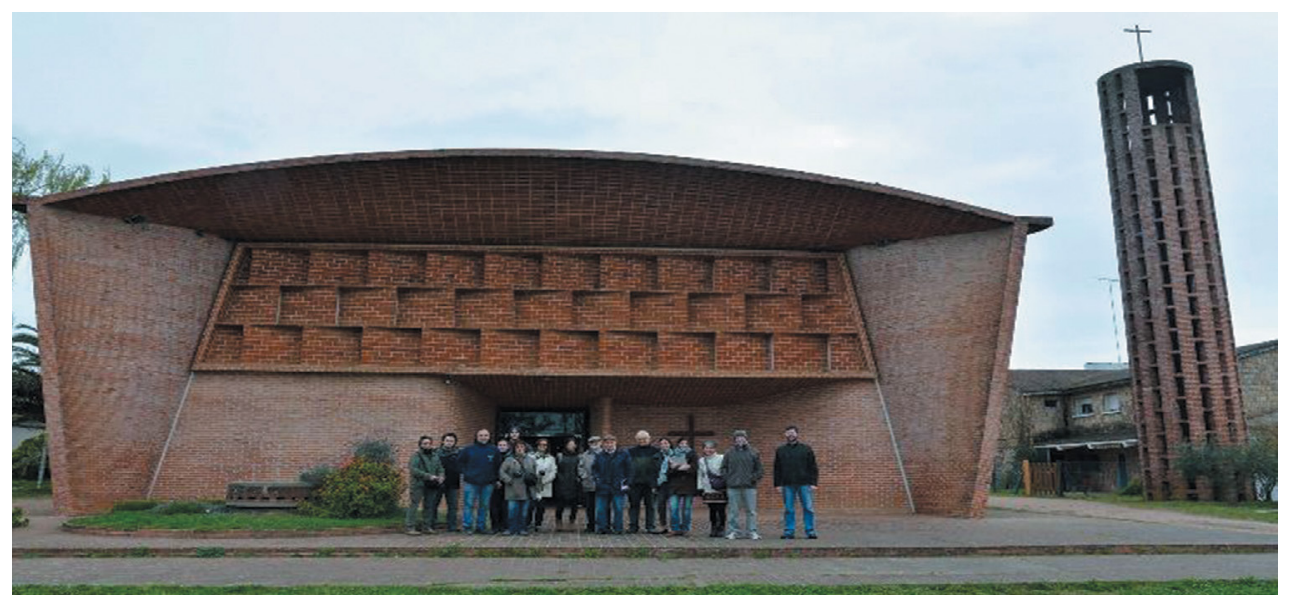

Figure 4: Picture of front façade of Church of Christ the Worker. 


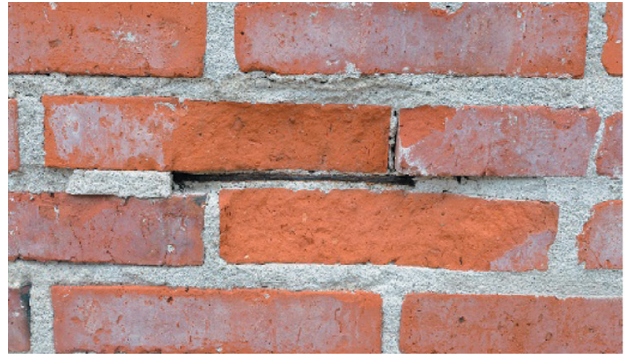

(a)

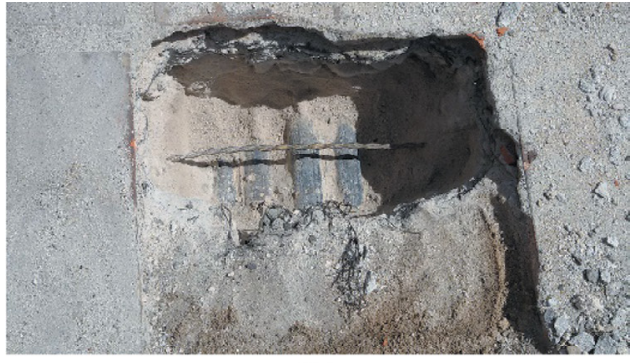

(b)

Figure 5: (a) Corrosion with exposed rebar and mortar detachment in the church building and (b) actual state of tie rods in the roof's valleys.

The walls and ceiling of the baptistery had presence of moisture. As Figure 6a shows, ponding had occurred at some parts of the baptistery's floor. In other parts of the structure, particularly the valleys of the church's roof, presence of moisture was also visually detected, although to a lesser extent than in the baptistery. Finally, partial degradation of mortars was detected in several zones, especially in those exposed to rain. Figure $6 \mathrm{~b}$ shows the biological colonization and deterioration of mortars by phototropic organisms.

\subsection{Non-destructive Testing Techniques}

\subsubsection{Infrared Thermography}

Both passive and active infrared thermography approaches were useful to detect areas with differences in moisture content and some symptoms of damage in the church's walls.

With respect to the passive approach, a general inspection was performed looking for differences in temperature patterns. The colder areas were further investigated and compared with other parts of the structure. On the one hand, as Figure 7 shows, general presence of moisture was primarily detected in the valleys of the church's ceiling; this was confirmed later in a closer inspection. General presence of moisture was also detected in the baptistery, particularly close to the foundation of the retaining walls. These two results match with those obtained from the visual inspection. The presence of moisture in the exterior walls of the

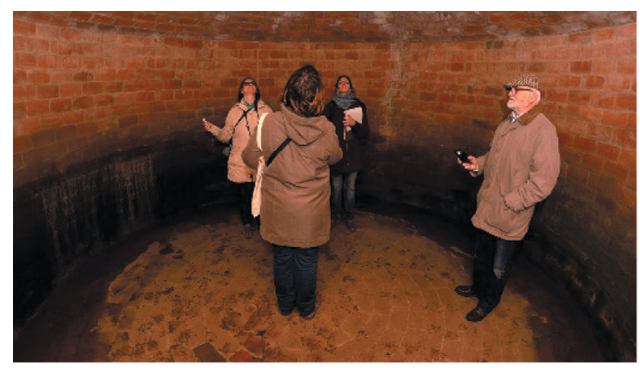

(a)

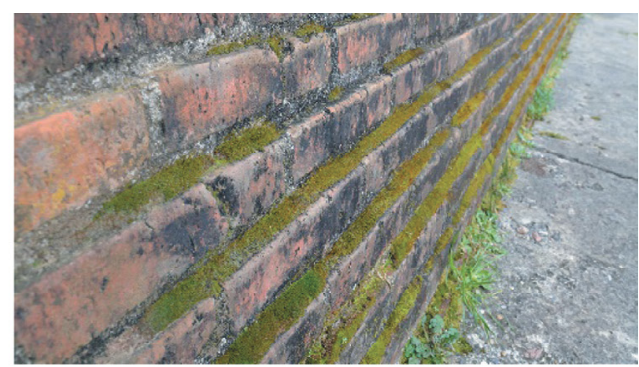

(b)

Figure 6: (a) Ponding at some parts of the baptistery's floor and (b) biological colonization and deterioration of mortars by phototropic organisms. 


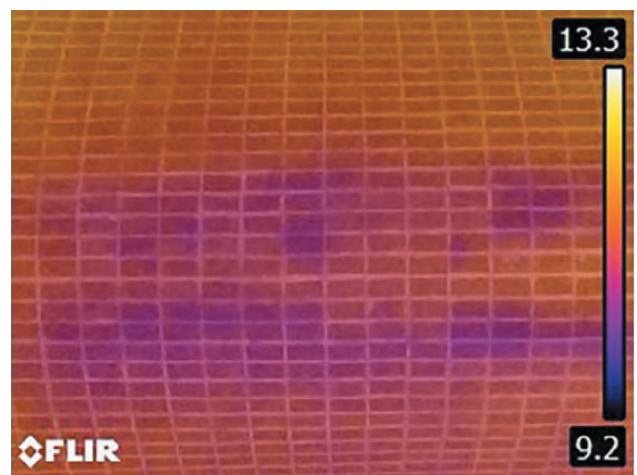

(a)

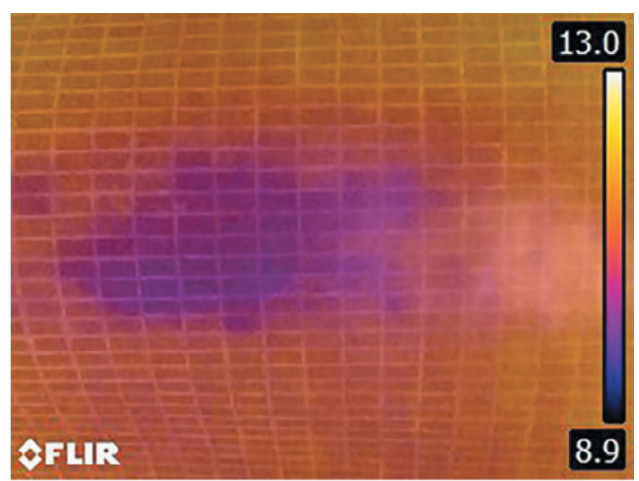

(b)

Figure 7: Presence of moisture in the valleys of the church's ceiling.

church could not be assessed because, given that these walls are curved, there were zones with different exposition to rain and wind. On the other hand, some symptoms of damage were detected in the church's ceiling; e.g. figure 8a shows some loose ceramic titles.

Active infrared thermography was carried out on the roof and on the internal surface of the church's walls. This approach was not able to show any new results different from those obtained with the passive approach. Regarding the second location, this technique was used to look for the extension of the damage in the church's walls. With this procedure it was possible to determine the extension of the damaged zone, as Figure $8 \mathrm{~b}$ shows.

\subsubsection{Ground Penetrating Radar}

GPR was applied to detect moisture content in the east and west façades of the church at multiple heights and in the perimeter of the retaining walls of the baptistery. This technique was useful, in the first case, to detect variations in the moisture content, and in the second case, to confirm the results obtained with the visual inspection and infrared thermography, i.e. severe presence of moisture, particularly close to the foundation of the retaining walls.

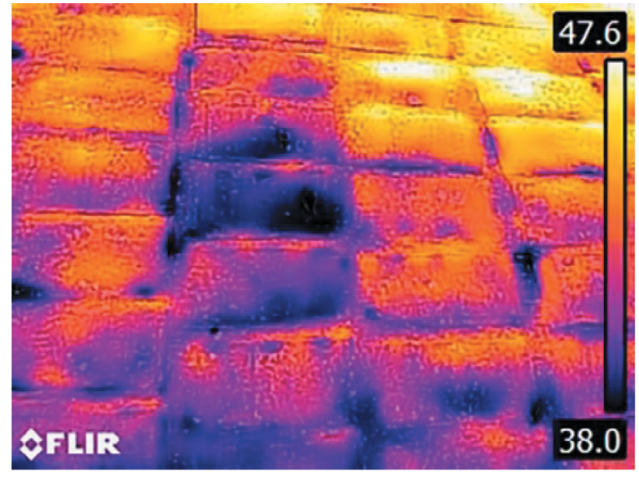

(a)

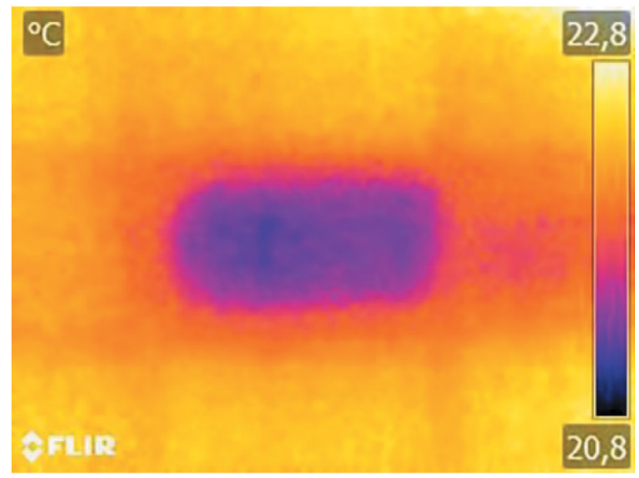

(b)

Figure 8: Symptoms of damage in the ceiling and walls of Dieste's church. Thermal images showing (a) an area with some loose ceramic tiles and (b) a loose ceramic brick after two hours of exposure to two halogen lamps. 


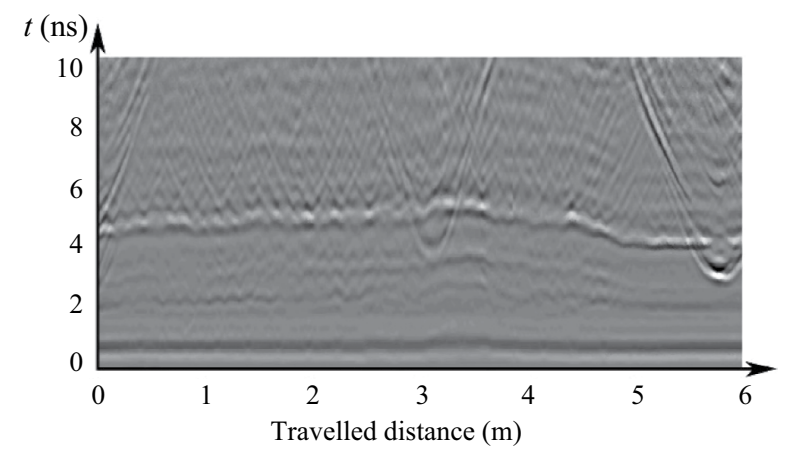

Figure 9: Horizontal GPR profile of a part of church's curved walls.

Figure 9 shows a horizontal GPR profile of the part of Dieste's church curved walls. It can be seen that, in the scanned zone, the EM pulse arrival time changes while the travelled distance varies. More precisely, the arrival time is greater in the centre of the profile - where the inclined geometry of the walls and the edge beam do not provide rain protection to the walls - than in the beginning and end of it - where the walls are indeed protected to rain. Given that these measurements were taken one day after a heavy rain event, it is reasonable to think that differences in arrival times are due to variations in moisture content.

References $[15,17]$ were used to estimate these variations of moisture content in the walls. For handmade type of bricks, eqn (4) is retained:

$$
\sqrt{\varepsilon}=a \cdot \omega+b=9.6703 \cdot \omega+1.6727 .
$$

The relationship between the variation of moisture content $(\Delta \omega)$ and the variation of the EM pulse arrival time $(\Delta t)$ is presented in eqn (5) and was founded from eqns (2) and (4) - where $d=0.48 \mathrm{~m}$ is twice the thickness of the wall without having into account the air chamber:

$$
\Delta \omega=\frac{c}{a \cdot d} \cdot \Delta t=6.5 \times 10^{7} \mathrm{~s} \cdot \Delta t
$$

This relationship was applied to quantify the variation of moisture content along the church's walls. Figure 10 presents $\Delta \omega$ as a function of the travelled distance for the GPR profile shown in Figure 9. In Figure 10, the blue zone corresponds to a ridge while the red

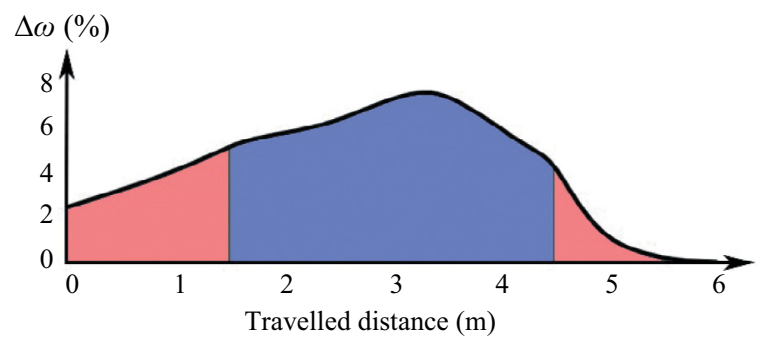

Figure 10: Variation of moisture content $(\Delta t)$ as a function of the travelled distance. 


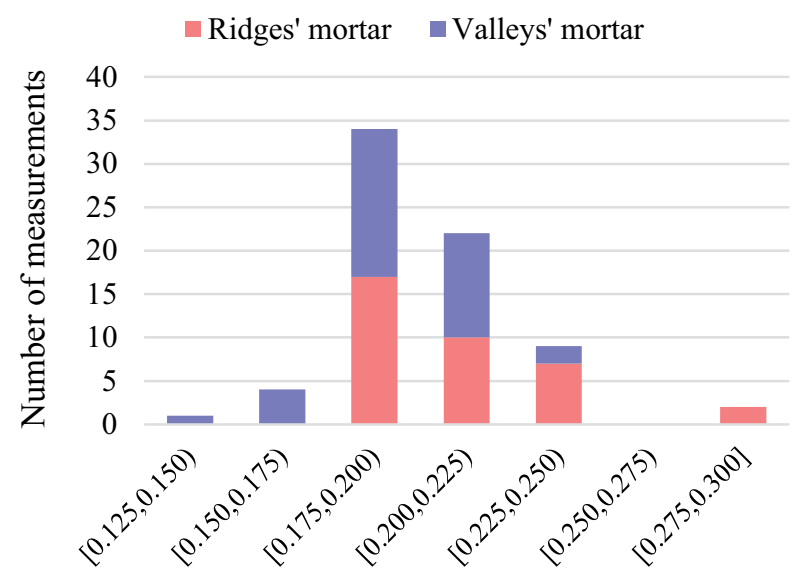

Pin penetration (inches)

Figure 11: Penetration resistance results on the mortar of church's exterior walls.

one corresponds to two consecutive half-valleys. The average difference in moisture content between the valleys and ridges of the walls was approximately equal to $4 \%$.

\subsubsection{Penetration Resistance}

This NDE technique was applied on both the bricks and mortars of different parts of the structure. Figure 11 presents the results on the mortar of church's exterior walls. In this case, Windsor pin was used in three inspection points per valley and three inspection points per ridge, giving a total of 36 points per façade - west and east.

Figure 11 shows that the ridges' mortar tended to yield higher penetration results - values towards the right in Figure 11 - valleys' mortar. A more detailed analysis indicates that the average pin penetration on ridges' mortar is 0.208 inches while on valleys' mortar is 0.194 inches. A two-sample $t$-test assuming equal variances reveals that the $t$-value is equal to 2.42 , which implies that the means of the two groups can be assumed as statistically independent from each other [25]. In addition to the comparative analysis, the penetration resistance values represent a good way of estimating of the mortar compressive strength, since these two quantities are inversely correlated between them [20,21]. This data will improve the developing of a numerical model of the structure, which will be performed by another subgroup of the project working group.

Table 1 presents the penetration resistance results of healthy and damaged bricks of the church's interior and baptistery. Although penetration resistance is not usually applied on bricks [12], the results show that there is a difference between healthy and damaged bricks. The average pin penetration on healthy bricks is 0.159 inches while on damaged bricks is 0.199 inches. When making a two-sample $t$-test assuming equal variances, the $t$-value results equal to 3.23, which means that the means of the two groups can be assumed as statistically independent from each other [25]. This means that this NDE technique may be useful to detect some symptoms of damage in ceramic bricks. 
Table 1: Penetration resistance results on different bricks of the structure.

\begin{tabular}{ccccc}
\hline \multirow{2}{*}{ Inspection point } & \multicolumn{4}{c}{ Pin penetration (inches) } \\
\cline { 2 - 5 } & \multicolumn{2}{c}{ Healthy bricks } & \multicolumn{2}{c}{ Damaged bricks } \\
& Church's interior & Baptistery & Church's interior & Baptistery \\
\hline 1 & 0.148 & 0.203 & 0.167 & 0.219 \\
2 & 0.139 & 0.178 & 0.200 & 0.223 \\
3 & 0.142 & 0.197 & 0.160 & 0.175 \\
\hline
\end{tabular}

\subsubsection{Ultrasonic Testing}

Ultrasonic testing technique was not useful to detect significant differences between healthy and damaged bricks. Although the mean results of UPV were slightly different between them $-1,637$ and $1,436 \mathrm{~m} / \mathrm{s}$, respectively - the variances are not high enough to state that the two samples are statistically different from each other [25]. This was concluded by doing a two-sample $t$-test assuming equal variances. This result is in agreement with Ref. [24], where measured the amplitude of the first peak of the P-waves to characterize damaged joints since UPV presented very large variations. Moreover, the UPV values were, in certain cases, highly affected by the moisture content of the bricks.

Even though they are not suitable for the detection of pathologies and damage, the UPV results are an excellent database to estimate the dynamic modulus of elasticity of the materials - bricks and mortars - of the structure [16]. The dynamic modulus of elasticity represents a good way of estimating the static modulus of elasticity [12,16], and therefore, provides a very important input for the numerical modelling of the structure.

\section{CONCLUSIONS}

Church of Christ the Worker constitutes an important piece of the Uruguayan heritage, hence the need to preserve it. Keeping It Modern program has offered the possibility of evaluating the current state of the structure with the objective of creating a conservation plan and an administration system of the church.

The visual inspection campaign showed that the overall building's integrity is in very good condition. Only particular pathologies were identified at specific locations. These were the presence of moisture in some parts of the church, mainly in the baptistery and to a lesser extent on the roof's valleys; corrosion of steel reinforcement rebars, in many cases being exposed due to mortar detachment; and some deterioration of mortars.

The conjunction of the four NDE techniques used yielded results associated with various symptoms of initiated deterioration mechanisms, such as presence of moisture, degradation of mortars and damage of bricks. The following results are retained:

1. Infrared thermography was useful to detect the presence of moisture in both the baptistery and the valleys of the church's ceiling. These two results match with those obtained from the visual inspection.

2. GPR, in turn, was valuable to detect the presence of moisture in the valleys of the church's walls. Moreover, the applied procedure allows the estimation of the moisture content.

3. The visual inspection and both the infrared thermography and GPR are conveniently complementary. Their application allows a fast and precise assessment of the moisture content with a minimal intervention of the structure. 
4. Penetration resistance technique provided good results regarding the evaluation of mortar deterioration. Symptoms of damaged bricks could be assessed with the infrared thermography and penetration resistance techniques.

5. Both penetration resistance and ultrasonic testing will improve the elastic properties knowledge, which will be an input for the numerical model of the structure.

Non-destructive testing techniques applied to the church were able to provide qualitative and quantitative information regarding the building's health condition. This information will be a very useful source for forthcoming maintenance plans in order to succeed in preserving the church's condition in the most efficient way.

Despite the presence of moisture, the corrosion of some steel bars and the degradation of mortars that are commonly present in aged RBM structures, the church is in a good state of preservation. This fact reveals the impressive care with which it was designed and built.

\section{ACKNOWLEDGEMENTS}

The authors would like to acknowledge the financial support of the programme provided by Getty Foundation and Keeping It Modern grant. They also wish to thank the members of the programme working group for the excellent teamwork that was possible. Last but not least, assistance provided by Bach and Cinthia Planchón is greatly appreciated.

\section{REFERENCES}

[1] Amrhein, J.E. \& Porter, M.L., Reinforced Masonry Engineering Handbook: Clay and Concrete Masonry, Masonry Institute of America \& International Code Council: Washington, DC, 2009.

[2] Taly, N., Design of Reinforced Masonry Structures, McGraw-Hill: New York, 2010.

[3] Pedreschi, R. The Engineer's Contribution to Contemporary Architecture, Thomas Telford: London, 2000.

[4] Mas Guindal, A.J. \& Adell, J.M., Eladio Dieste y la cerámica armada en Uruguay. Informes de la Construcción, 56(496), pp. 13-23, 2005. DOI: 10.3989/ic.2005.v57. i496.459.

[5] Caraballo, C., La obra de Eladio Dieste: El reto del expediente para su inclusión en la Lista del Patrimonio Mundial. Cuadernos del Claeh, 34(102), pp. 249-265, 2015. http://publicaciones.claeh.edu.uy/index.php/cclaeh/article/view/196/166 (accessed 21 February 2017).

[6] Anderson, S., 'Dance Without Effort or Fatigue': The architecture of Eladio Dieste, Eladio Dieste: Innovation in Structural Art, ed. Anderson, S., Princeton Architectural Press: New York, pp. 32-41, 2004.

[7] Allen, E., Guastavino, Dieste, and the two revolutions in masonry vaulting. Eladio Dieste: Innovation in Structural Art, ed. Anderson, S., Princeton Architectural Press, New York, pp. 66-75, 2004.

[8] Pedreschi, R. \& Larrambebere, G., Technology and innovation in the work of Eladio Dieste. Eladio Dieste: Innovation in Structural Art, ed. Anderson, S., Princeton Architectural Press: New York, pp. 138-151, 2004.

[9] Dieste, E., Iglesia en Montevideo: Templo parroquial de Atlántida. Informes de la Construcción, 13(127), pp. 43-56, 1961. DOI: 10.3989/ic.1961.v13.i127.5106.

[10] Anderson, S., Eladio Dieste: Innovation in Structural Art, Princeton Architectural Press: New York, pp. 42-55, 2004. 
[11] The Getty Foundation. Keeping it modern architectural conservation grants Web Site, http://www.getty.edu/foundation/initiatives/current/keeping_it_modern/ (accessed 22 February 2017).

[12] Suprenant, B.A. \& Schuller, M.P., Nondestructive Evaluation \& Testing of Masonry Structures, Hanley-Wood: Addison, IL, 1994.

[13] Shuller, M.P., Nondestructive testing and damage assessment of masonry structures. Proceedings of the RILEM/NSF International Engineering Research and Education Workshop "In-situ Evaluation of Masonry and Wood Historic Structures: Challenges and Opportunities”, Prague, Czech Republic, pp. 67-86, 2009.

[14] Cangel, Y.A., Introduction to Thermodynamics and Heat Transfer, McGraw-Hill: New York, 2009.

[15] Domenech, L.D., Cetrangolo, G.P., Moltini, G. \& Morquio, A.A., Methodology for the detection and quantification of the moisture content in ceramic masonry structures. Proceedings of the 16th International Brick and Block Masonry Conference, Padua, Italy. 2016.

[16] Bungey, J.H., Millard, S.G. \& Grantham, M.G., Testing of Concrete in Structures, Taylor \& Francis: London and New York, 2006.

[17] Cetrangolo, G.P., Domenech, L.D., Moltini, G. \& Morquio, A.A., Determination of moisture content in Ceramic Brick walls using ground penetrating radar. Journal of Nondestructive Evaluation, 36(12), 2017. DOI: 10.1007/s10921-016-0390-4.

[18] Binda, L., Colla, C. \& Forde, M.C., Identification of moisture capillarity in masonry using digital impulse radar. Construction and Building Materials, 8(2), pp. 101-107, 1994. DOI: 10.1016/s0950-0618(09)90019-8.

[19] Annan, A.P. Electromagnetic Principles of Ground Penetrating Radar (Chapter 1). Ground Penetrating Radar Theory and Applications, ed. Jol, H.M., Elsevier Science: Oxford, pp. 3-40, 2009.

[20] Malhorta, V.M. \& Carino, N.J. Handbook on Nondestructive Testing of Concrete, CRC Press, New York, 2004.

[21] Felicetti, R. \& Gattesco, N., A penetration test to study the mechanical response of mortar in ancient masonry buildings. Materials and Structures, 31, pp. 350-356, 1998. DOI: $10.1007 / \mathrm{BF} 02480678$.

[22] ASTM C803 / C803M-17, Standard Test Method for Penetration Resistance of Hardened Concrete, ASTM International: West Conshohocken, PA, 2017.

[23] ASTM C597-16, Standard Test Method for Pulse Velocity Through Concrete, ASTM International: West Conshohocken, PA, 2016.

[24] Cetrangolo, G., Morquio, A., Aulet, A. \& Spalvier, A., Diagnóstico del estado de muros de mampostería en edificación patrimonial de finales del siglo XIX mediante la aplicación de ensayos no destructivos. Proceedings of the Congreso Latinoamericano sobre Patología de la Construcción, Tecnología de la Rehabilitación y Gestión del Patrimonio (REHABEND), Santander, Spain, 2014.

[25] Hines, W.W., Montgomery, D.C., Goldsman, D.M., Borror, C.M., Probability and Statics in Engineering, John Wiley and Sons: New York, 2003. 